\title{
Los menores marroquíes en Bizkaia, un colectivo en cuarentena social
}

Moroccan minors in Bizkaia, a collective in social quarantine

Mikel Barba del Horno · mikelbarba@gmail.com

Recibido: 17/06/2019

Aceptado: 02/11/2019

\section{Resumen}

Este artículo estudia las características del modo de incorporación de los Menores extranjeros no acompañados (MENA) de origen marroquí en Bizkaia. A partir del análisis de una serie de entrevistas en profundidad realizadas a exMENAs, veremos cómo el colectivo se encuentra en una situación que podríamos definir como de cuarentena social, que se caracteriza por la restricción del acceso a la mayoría de los espacios de socialización normalizados. Esta situación de aislamiento impide a los MENAs establecer relaciones que proporcionen capital social puente, dificultando la adquisición de los repertorios culturales que les permitirían tener una integración satisfactoria.

Palabras clave: Capital social, inmigración, menores extranjeros no acompañados, incorporación.

\section{Abstract}

In this article we are going to explore the incorporation process of Moroccan unaccompanied foreign minors in the province of Bizkaia (Spain). Through the analysis of a set of in-depth interviews we are going to_explore/ explain how this collective is in a situation of a so-called social quarantine, characterized by an absence of access to the normalized socializing spaces. This isolation leads to a lack of bridging social capital, which hinders the acquisition of cultural repertoires that will allow a satisfactory integration.

Keywords: Social capital, inmigration, unaccompanied foreign minors, incorporation.

Los Menores Extranjeros No Acompañados (MENAs) constituyen un tipo de migración que se inicia en Europa a mediados de la década de los noventa y que se caracteriza por la llegada de inmigrantes menores de edad, fundamentalmente africanos, sin acompañamiento de adultos. Constituyen un problema específico para las administraciones porque, de acuerdo a la legislación del menor, el Estado debe hacerse cargo de estos menores y no puede recurrir a la expulsión. 
El fenómeno MENA se inicia en España y en la Comunidad Autónoma Vasca (CAV) en los años 90 y llega a su máxima expresión en los últimos años de la primera década del 2000. Con la crisis económica que se inicia en 2008 se da una tendencia al estancamiento o a la reducción y, en tiempos recientes, la recuperación económica ha dado lugar a una nueva oleada de llegadas que está generando dinámicas similares a las del período estudiado.

La mayoría de los MENAs que llegan a España son de origen marroquí —en torno al 67\% según datos de 2007-. En el caso de la CAV el porcentaje de marroquíes sobre el total es aún mayor, llegando a representar el 88\% en 2007. En el período estudiado casi la totalidad de los menores acogidos eran varones.

La bibliografía existente en torno a los MENAs en Bizkaia ha abordado los temas de la descripción del colectivo (cuantificación, diferentes perfiles, etc.) y de la inserción en el sistema de acogida y los problemas que ello ha generado (Ararteko, 2005), (Setién y Barcelo, 2007), (Quiroga et al., 2009), (Gozalo et al., 2010), (Ararteko, 2011), (Mendoza y Belarra, 2015), (Cónsola, 2016). Según esta bibliografía, los motivos de la migración son en su mayoría socioeconómicos, en la mayoría de los casos emigran para mejorar su situación o la de su familia.

Los MENAs son acogidos en Bizkaia a través de un sistema diferenciado respecto a los menores autóctonos. La principal diferencia es que son acogidos mayoritariamente en grandes centros, separados de los núcleos urbanos. La saturación de estos centros ha dado lugar a problemas de convivencia y conflictos que se han difundido a través de los medios de comunicación generando una imagen muy negativa del colectivo de MENAs.

Los MENAs son un colectivo que sufre uno de los estigmas más extremos. Por un lado, pertenecen al colectivo marroquí, un colectivo que sufre en España un estigma muy negativo que lo relaciona con la violencia, la delincuencia, las agresiones sexuales, etc. (Cea D’Ancona y Ochando González, 2012). El marroquí es, también, el colectivo inmigrante peor valorado en el País Vasco (Ikuspegi, 2018). Por otro lado, en el caso de los jóvenes, a los elementos de este estigma se le suma la imagen de conflicto y violencia asociada a los centros de menores. Como veremos, los jóvenes marroquíes sufren una situación de estigma y aislamiento incluso respecto a la comunidad marroquí e islámica adulta. Este estigma extremos está en el origen de los mecanismos de cierre social que van a dar lugar a que el colectivo se encuentre en una situación de cuarentena.

El objetivo de este trabajo ha sido definir las características fundamentales del modo de incorporación de los Menores Extranjeros no Acompañados (MENAs) de origen marroquí en Bizkaia. El fenómeno de los MENAs está generando actualmente un importante debate debido a un aumento reciente de este tipo de inmigración y a la implicación directa que tienen las administraciones públicas en la gestión de la misma, al tratarse de personas menores de edad. Como veremos en el artículo la gestión del fenómeno MENA se ha abordado desde un punto de vista centrado en el aislamiento del colectivo y ha conducido a una integración fallida de estos jóvenes. 


\section{MARCO TEÓRICO Y METODOLOGÍA}

Desde un punto de vista teórico, partimos de que el capital social (Portes, 1998), (Bourdieu, 1986, pp. 51-53) es un factor central en los procesos de incorporación de los inmigrantes. La integración de los inmigrantes pasa por la adquisición de nuevos repertorios culturales (Swidler, 1986: 277) que les permitan lograr una inserción satisfactoria en la sociedad de acogida. Para ello es necesario que se produzcan interacciones con la población autóctona que permitan a los inmigrantes entrar en contacto con la cultura del lugar de recepción. Estos contactos e interacciones constituyen lo que, en la literatura sociológica, se denomina capital social puente (Putnam, 2007). El capital social puente ha sido identificado en diferentes investigaciones como un elemento clave para desarrollar estrategias económicas de movilidad ascendente (Granovetter, 1973), (Burt, 2001).

El capital social vínculo (Putnam, 2007), por su parte, se genera a partir de contactos entre miembros de un mismo grupo étnico. La existencia de capital social vínculo es importante en los procesos de incorporación de los inmigrantes porque vincula a los inmigrantes recién llegados con otros de su mismo origen que se encuentran más asentados en la sociedad de recepción. Este tipo de capital facilita el acceso al mercado de trabajo (Waldinger, 1997) o la puesta en marcha de pequeñas empresas (Light, 1984).

Como veremos en el artículo, la sociedad de acogida, especialmente a través de la acción de las administraciones públicas, despliega una serie de prácticas de cierre social que limitan el acceso a espacios y el contacto de los MENAs con la población autóctona, e incluso con la población inmigrante más asentada, limitando de esta manera las posibilidades de una inserción satisfactoria a través de los dos tipos de capital social. A lo largo del artículo se exponen cuatro mecanismos de cierre: los centros de menores, la inserción en el sistema educativo, el cierre de los espacios de ocio y la limitación en el acceso a espacio de socialización religiosos, concretamente la mezquita.

Estos mecanismos de cierre dan lugar a un modo de incorporación (Borocz y Portes, 1989) que se caracteriza por el aislamiento del colectivo de MENAs. Denominaremos a este modo de incorporación «cuarentena social». La cuarentena social impide a los jóvenes marroquíes poner en marcha estrategias de integración basadas en el capital social puente porque limita el contacto con la población autóctona. Limita de esta manera las posibilidades de movilidad social ascendente (Granovetter, 1973) y de adquisición de repertorios culturales (Swilder, 1986) nuevos que les permitan una integración más satisfactoria. La situación de cuarentena también limita los contactos con los colectivos de inmigrantes adultos más asentados que podrían proporcionar acceso a recursos como ayuda financiera, contactos laborales, apoyo residencial etc. Estos recursos son especialmente importantes al cumplir la mayoría de edad y tener que abandonar el centro. En este sentido limitan también la posibilidades de incorporación a través del capital social vínculo, especialmente importante en las situaciones de gran vulnerabilidad (Granovetter, 1973). 
Es especialmente significativo el hecho de que se trata de un colectivo sobre el que el Estado tiene una intervención muy directa a través de la acción de los servicios de infancia. La acción del Estado contribuye en este caso a un mayor aislamiento, a una mayor visibilización, problematización y estigmatización de los menores extranjeros derivada en gran medida de la política de acogida en grandes centros, como se mencionó anteriormente.

Desde el punto de vista metodológico el principal instrumento de recogida de información ha sido la elaboración de entrevistas en profundidad. Se han realizado 25 entrevistas a jóvenes marroquíes residentes en Bizkaia, mayores de edad, pero que han estado acogidos en los centros de menores de la provincia en los años previos a la realización del estudio. En el momento de realizar las entrevistas, los jóvenes entrevistados eran usuarios de programas de emancipación de la Diputación Foral de Bizkaia y se encontraban en un proceso de inserción social tutelado por educadores sociales.

Se ha entrevistado también a profesionales y miembros de asociaciones que tienen relación con el colectivo: educadores/as, responsables de centros y asociaciones, profesores/as de enseñanza reglada, representantes de organizaciones islámicas, etc.

La metodología utilizada al hacer las entrevistas ha sido cualitativa. Se ha utilizado un modelo de entrevista semiestructurada en la que se ha partido de guiones pero dejando hablar libremente a los entrevistados. De esta manera han surgido temas que no estaban previstos en el guión o que se han enfocado desde ángulos no preconcebidos. Algunas entrevistas se han desarrollado a lo largo de una única sesión mientras que, en otros casos, se han prolongado a lo largo de diferentes sesiones. Se ha tenido acceso, además, a entornos informales en los que se han podido observar diferentes interacciones sociales. La recogida de información se ha realizado entre los años 2011 y 2014.

A partir de las entrevistas se han llegado a identificar cuatro mecanismos de cierre social que aparecían de forma recurrente en las mismas. Se ha seguido el procedimiento de generalización analítica propuesto por Yin $(2003,3)$, en la que, a partir de una serie de casos empíricos concretos, se generaliza a una teoría y no a una población, como en el caso de las generalizaciones de tipo cualitativo.

La estructura del artículo comienza con la definición del colectivo y del fuerte estigma al que está sometido. Este estigma está en el origen del aislamiento social que sufre este grupo. En los siguientes apartados se presentan los cuatro mecanismos de cierre social que dan lugar a la situación de cuarentena. 


\section{EL CENTRO DE MENORES COMO DISPOSITIVO DE AISLAMIENTO}

La mayoría de los MENAs que se incorporaron al sistema de protección de menores en Bizkaia durante el período estudiado fueron acogidos en grandes centros apartados de las zonas urbanas (Quiroga et al., 2009). Esta fue la modalidad de acogimiento exclusiva en la primera etapa de llegadas de MENAs a Bizkaia a finales de los 90 y principios de los 2000, y todavía hoy sigue siendo la modalidad más importante.

Podríamos decir que el centro de menores es el elemento más representativo de esa categoría de la que hablábamos anteriormente: la cuarentena social, una situación que se caracteriza por el cierre de los espacios sociales y físicos a los menores inmigrantes.

Describamos, en primer lugar, la situación de algunos de estos centros de menores. Son centros caracterizados por estar en localidades pequeñas y/o en barrios apartados rodeados por un número muy reducido de viviendas y alejados de los núcleos urbanos. Ejemplos de este tipo de centro serían el centro Zabaloetxe en la localidad de Loiu, el centro de Izurtza, el centro de primera acogida de Amorebieta, el centro residencial El Vivero en Galdakao o el ya cerrado centro de Orduña, entre otros. En ocasiones ni siquiera existe un servicio de transporte público que pase cerca, como en el caso del centro El Vivero y la movilidad de los menores depende de que se realicen transportes en furgoneta a cargo de los educadores.

Las normas de los centros, los horarios marcados, la necesidad de desplazarse y la inserción en el sistema educativo, que analizaremos más adelante, son también elementos que condicionan de manera importante las posibilidades de contacto de los menores extranjeros con población autóctona.

Las normas en los centros de menores forman parte de un diseño disciplinario propio de una institución total. Las normas regulan todos los aspectos de la vida de los menores: horarios de salida, de comidas, higiene, ropa, idioma en el que se comunican en presencia de educadores, etc.

En Amorebieta, como hay mucha gente, hay problemas. Si hay mucha gente, hay problemas, si no es entre chicos, era con los educadores. Gente que no entendía bien. La forma de vivir, los baños están llenos de agua. (Joven marroquí 13)

Como observamos en este testimonio, la institución total tiende a crear problemas derivados de su propio funcionamiento, de su exceso de normas, por otra parte necesarias para hacer viable la convivencia entre un número importante de personas atravesadas por relaciones de autoridad, etc. A continuación, podemos leer un testimonio de un joven que ha estado en un piso de emancipación y en el centro de Izurtza: 
Estoy mucho mejor porque cuando vas a un piso no es lo mismo. En el centro hay muchas normas, muchos problemas, muchos chicos, mucha gente que no se entendía. En un piso estás más tranquilo. Puedes levantar, tomar algo cuando quieras. La comida la cocinábamos nosotros. Es un buen cambio. (Joven marroquí 13)

El rechazo a las normas aparece también en el caso de los menores no conflictivos o que presentan un comportamiento más ajustado a las normas. A continuación, presentamos el testimonio de dos menores que se caracterizan por un buen comportamiento respecto a las normas; pero que también tienen una opinión negativa respecto a las mismas.

En Amorebieta muy, muy mal, los educadores son muy majos pero las normas muy malas. Hay mucha gente. Me dijeron que hace cuatro años hay gente que duerme en el suelo. (Joven marroquí 14)

Las normas son buenas para los chavales que son malos pero son malas para los chavales que son buenos. (Joven marroquí 15)

En Izurtza había una (educadora) que era mala. A las 10 teníamos que ir a la cama. Los que estamos en el cuarto, 6, en literas, no nos dejaba hablar. Si te pilla hablando, te quita la paga, sin salir. Era muy estricta. Una vez les estaba cortando el pelo a unos amigos míos y eran las 10 y algo y era un fin de semana, pues tuve que meterme a la cama sin ducharme porque me obligó ella, sin ducharme. Llegas (de trabajar) con el ruido de las máquinas, tienes que andar una hora, luego le saludas «hola» y se enfada contigo sin ningún motivo. No te hablo porque estoy cansado. No es como ellos que pasan el día sentados. Había muchos chavales que gritaban que llegaban tarde al centro, hablaban mal, discutían más. (Joven marroquí 13)

Como apuntábamos anteriormente, el centro se convierte en un espacio de socialización central para estos menores, en ocasiones en un espacio de cuasi reclusión y, en este sentido es descrito por algunos jóvenes como algo parecido a una cárcel. Estar en un centro apartado limita de manera importante la posibilidad de conocer a otros jóvenes autóctonos, por lo que el contacto social tiende a limitarse a relaciones con otros menores que se encuentran en el centro.

La forma de conocer a chicos españoles era a través del CIP en Bilbao. ... En Bilbao tengo más posibilidades, en el centro es como una cárcel. Cuando sales del centro, das una vuelta. Tienes que volver a las 9 para que te llegue la hora. (Joven marroquí 13)

Entre semana no salimos, no hay tiempo. Hay viernes que no trabajamos y daban creditrans para bajar a la mezquita bajamos a la mezquita de Bilbao. (Joven marroquí 1)

La masificación en los centros, la falta de actividad y de expectativas o la falta de personal generan en muchos momentos situación de tensión y de conflicto, dando lugar en momentos puntuales a estallidos graves, como el que condujo al motín del centro de Orduña o al 
incendio del centro de Amorebieta (Quiroga et al., 2009: 278-279). Las noticias relativas a conflictos en los centros han creado en Euskadi cierta alarma social en torno a los MENAs. El centro se convierte en parte del estigma que sufren estos menores. Como describe un profesor:

Estos estaban en un centro que tenía muy mala fama por sus relaciones con lo gente de alrededor. El centro les marca mucho, cuando salían fuera eran «el del centro» porque los medios de comunicación crearon una imagen muy mala de los centros de menores extranjeros. Algunos cuando fueron a Donosti pudieron respirar, porque podían ir por la calle sin que pensaran que iban a robar. (Profesor centro educativo)

Los pisos de emancipación son una segunda modalidad de acogida de los menores extranjeros que se aplica en los casos en los que se da una mejor conducta. No son recursos apartados; están integrados en los espacios urbanos, el número de menores que habitan estos recursos es sustancialmente menor, lo que da lugar a una menor conflictividad y a una menor visibilidad.

La estancia en pisos permite a los menores tener una mayor interacción con el entorno, ampliar sus relaciones sociales etc. Para los menores que ingresan en este tipo de recursos después de estar en un gran centro, el cambio supone una mejora importante en sus condiciones de vida.

Entre los pisos y el centro hay mucha diferencia. Cuando sales y te mandan a esos pisos ellos te apuntan para que hagas un curso. Empiezo a hacer un CIP, por la tarde me dejan salir pero hay que volver a las $9 . .$. Te mandan una tarea de que haces algo en casa. (Joven marroquí 3)

Estoy mucho mejor porque cuando vas a un piso no es lo mismo. En el centro hay muchas normas, muchos problemas, muchos chicos, mucha gente que no se entendía. En un piso estás más tranquilo, puedes levantar, tomar algo cuando quieras. La comida la cocinábamos nosotros. Es un buen cambio. (Joven marroquí 13)

Me cambiaron a un piso que no tienes educador, solo una vez a la semana. Como no tienes educador, no cumplimos el horario a veces. De todo hacemos, cuando no tienes educador. Al cambiar, te gusta salir todas las noches. Estás más a tu aire. (Joven marroquí 4)

En estos pisos los menores son mucho más independientes lo que les hace aprender a organizarse los horarios, las tareas del hogar etc. Los propios educadores de mayores de edad destacan que los menores que han estado previamente en pisos llegan mucho más preparados para llevar una vida autónoma que los que han estado en centros. (Educadora programa de emancipación).

Te dan una paga de un mes, 60 euros. Tienes que respetarla para que te llegue. Esta vez cojo 10, esta vez cojo 5, para que te llegue. En la comida nos organizamos. Tú haces la cena, el otro limpia... El fin de semana limpiamos la casa entre todos. (Joven marroquí 4). 
Por último, el ocio que pueden organizar los menores en estos pisos les va a poner en contacto con población autóctona normalizada, a través fundamentalmente de los contactos con chicas y la inscripción en equipos deportivos.

También podía coger el metro, salgo con mis amigos y venimos a Barakaldo, a buscar chicas. Entre semana y fines de semana. Vamos a Barakaldo, tenemos amigas, quedamos con ellas y hablamos. Vamos al parque, nos sentamos con ellas, charlamos. (Joven marroquí 3)

Al ser los menores extranjeros varones casi en su totalidad, si quieren relacionarse con chicas tienen que entrar en contacto necesariamente con población autóctona. Esta va a ser una de las vías de contacto que, como veremos, va a proporcionar a los menores el acceso a capital social puente y al capital cultural dominante.

Yo he estado con una chica española. A través de ella he conocido a más amigas. Ahora salgo con una amiga, hablamos. Por eso hablo castellano mejor. En el piso cuando sales a la calle conoces gente. Esto es mejor, te dejan salir por la tarde, dar una vuelta. (Joven marroquí 3)

Sin embargo, los menores acogidos en este tipo de recursos constituyen una minoría. Con el reciente aumento de llegadas de MENAs, la Diputación de Bizkaia está apostando de nuevo por la acogida en grandes centros.

\section{LA INSERCIÓN EN EL SISTEMA EDUCATIVO}

La inserción de los jóvenes marroquíes no acompañados en el sistema educativo vasco se produce siempre desde el punto de partida de que se trata de una población problemática. La inserción puede darse a través de dos tipos de centro, los que están orientados a tratar el fracaso escolar, que atienden a jóvenes que han fracasado en el sistema educativo ordinario; y los centros que están orientados a la inserción social, que están dirigidos a población en situación de exclusión social que carece de educación formal (Fernández y Barba, 2014).

Partiendo de esta distinción entre centros orientados al fracaso escolar y centros de inserción, en la entrevistas se aprecia que, en los centros orientados al fracaso escolar, siempre que no se produzcan dinámicas tendentes a convertirlos en guetos con una mayoría de alumnado inmigrante, los jóvenes marroquíes pueden tener acceso a unas serie de lazos informales con alumnado autóctono que puedan dar lugar a la creación de un capital social puente que les abra camino a espacios de socialización autóctonos. Sin embargo, al no ser el alumnado autóctono que acude a los centros orientado al fracaso escolar una población normalizada, el contacto entre ambos grupos también puede derivar en un refuerzo de la estigmatización mutua. La influencia del contacto 
con los jóvenes autóctonos en las clases del CIP es descrita de forma negativa por un profesor:

Los magrebíes, al principio de curso, eran bastante respetuosos, yo creo que estaban un poco a la expectativa; luego, cuando veían cómo se comportaban los autóctonos, ellos se empezaban a desmadrar también, a faltar al respeto.... Los fines de semana solían coincidir con los autóctonos en los mismos sitios de ocio. Ellos oían a los autóctonos hablar de los sitios e iban allí, pero cada uno con su grupo... Los chavales autóctonos también algunos tenían situaciones malas en casa y otros fingían un poco tenerlo, fingían provenir de un ambiente marginal, Y eso que les afectaba a los magrebíes porque su única referencia dentro de la sociedad autóctona eran estos chavales del CIP que se movían un poco por ambientes marginales. Yo creo que hubiera sido mejor que estudiaran con otro tipo de gente con más edad, con otros problemas y otros hábitos. (Profesor centro orientado al fracaso escolar)

Otra desventaja de los centros orientado al fracaso escolar es que no están tan preparados para afrontar situaciones de exclusión social del alumnado como la falta de recursos económicos, vivienda, etc.

Por el contrario, en los centros de inserción, se dispone de contacto con una red de recursos mayor (asociaciones orientadas a combatir la exclusión social, etc.). Sin embargo, el capital social que se genera tiende a ser autorreferencial - hacia el grupo de excluidos-y redundante. En estos centros es más difícil que se desarrollen relaciones que permitan o faciliten el acceso a espacios sociales en los que tengan acceso a la cultura autóctona. El alumnado de los centros de inserción social es mayoritariamente de origen inmigrante. También existe un tipo de alumnado autóctono de una edad más avanzada, en torno a los 25-30 años, con problemas de exclusión social.

El alumnado que acude al centro varía de año en año aunque, por lo general, es en cuanto a procedencia. Puede decirse que solemos tener un tercio de jóvenes marroquíes, un tercio de jóvenes latinoamericanos y un tercio de jóvenes autóctonos. Sin embargo, ha habido años en los que el noventa por ciento del alumnado era extranjero. (Profesor de centro de inserción)

Los contactos con alumnado autóctono y con alumnado latinoamericano pueden proporcionar, como en el caso de los centros orientados al fracaso escolar, alguna forma de capital social puente que permita un aprendizaje de nuevos repertorios culturales y que sea, desde este punto de vista, una vía para la integración social de los MENAs. Sin embargo, estos contactos pueden interpretarse como lazos entre grupos culturalmente heterogéneos, pero también como lazos dentro de un mismo grupo, el de los socialmente excluidos. Así, desde este punto de vista, la socialización segmentada de personas excluidas puede contribuir a agrandar la distancia respecto a la población autóctona considerada normal y a reforzar la identidad de excluido. 
En este sentido, podemos decir que el capital social que se deriva de las relaciones con el alumnado es un capital social vínculo, porque pone en contacto a los jóvenes marroquíes con otros jóvenes marroquíes u otros jóvenes extranjeros. Proporciona en este sentido lazos redundantes, que pueden contribuir a reforzar la posición de excluidos de estos menores. Esta situación también puede darse en centros orientados al fracaso escolar que, por las políticas de matriculación o por la cercanía a grandes centros de menores, tienen porcentajes muy altos de alumnado extranjero.

\section{EL CIERRE DE LOS ESPACIOS DE OCIO}

El tiempo de ocio es también un elemento fundamental en la socialización de las personas. En el caso de los jóvenes marroquíes en Bizkaia, vamos a ver cómo este colectivo se ve sometido a un cierre de parte de los espacios que la juventud emplea para socializarse en su tiempo de ocio. Especialmente en el caso de los menores que viven en centros, la posibilidad de acceder a espacios de ocio compartidos por la población autóctona es muy limitada.

\subsection{Prácticas racista de bares y discotecas}

El estigma es un elemento determinante en el conjunto de prácticas discriminatorias que conducen al cierre de los espacios de ocio. Es habitual, por ejemplo, que a los menores marroquíes se les niegue el acceso a los bares y discotecas. Estos son espacios que tienen una importancia vital en la socialización de los jóvenes, son espacios donde conocer gente y relacionarse. En el caso de los bares tenemos que, especialmente en los bares de fiesta y discotecas, se produce una exclusión generalizada de la población magrebí de estos espacios. La mayoría de los menores entrevistados mantiene que se le ha negado la entrada a los bares. La probabilidad de ser excluido en la entrada de los bares y discotecas depende, en gran medida, de si el menor presenta unos rasgos faciales que puedan ser más relacionados con la categoría de joven magrebí, digamos unos rasgos más típicamente moros.

Es difícil que hagas amigos, por ejemplo, de fiesta. A mí nunca me han parado al entrar a las discotecas pero a mis amigos marroquís no les dejan. (Joven marroquí 2)

En discotecas en Barakaldo no nos dejan, a mí y a más gente por ser marroquí. Una cosa es que me pilles robando pero que vaya la primera vez y no me dejas y ni siquiera me conoces... y ni siquiera he estado dentro y me dices que no... Te piden el DNI, se lo das y como pone marruecos... le pregunto por qué, ¿me lo puedes explicar?, por favor. Te dice no, no y te empuja. Nos gustaría que nos dijeran. Oye, si pillas a uno no le dejes entrar más. (Joven marroquí 13)

Si nos dejan entrar, entramos a bailar. Si no, nos sentamos y, cuando llega la hora, volvemos al centro. Estamos charlando. El portero dice: «mi jefe del trabajo me dice: los moros no pueden entrar». Aquí, en Barakaldo, no nos dejan entrar en ninguna. 
Tienes cara de moro. Como hay chicos malos, no nos dejan entrar. Ellos tienen que pensar que todos no somos iguales. Hay gente buena y mala. Hay gente de aquí que roba. Hay gente que roba bicicletas, que roba motores, en todos los lados. Hay gente buena y gente mala. (Joven marroquí 6)

\subsection{Sospechosos habituales: prácticas racistas de la policía}

Otro de los elementos que aparece recurrentemente en las entrevista es el de las continuas identificaciones y cacheos a los que se ven sometidos los jóvenes marroquíes por parte de la policía. Este proceder de la policía ha sido denunciado en numerosas ocasiones por organizaciones como SOS Racismo y se ha confirmado como una práctica oficial de la Ertzaintza al filtrarse a la prensa una circular en enero de 2014 en la que se alentaba a los agentes a identificar a jóvenes magrebíes en la zona de Barakaldo (El Correo 7/1/2014). El Ararteko abrió un expediente para pedir explicaciones al gobierno Vasco por esta circular. Los testimonios de los jóvenes concuerdan con estas prácticas:

A mí nunca me han cacheado pero pararme muchas veces. Te preguntan. Cuando no teníamos la residencia, te preguntan, a veces llaman al centro para ver si es verdad. Una vez nos pararon a un amigo y a mí en el Casco Viejo. Eran ertzainas, habían parado a unos chicos marroquís y estaba con un amigo, nos llamaron, nos pidieron el DNI y nos dijeron que no podíamos hablar entre los dos. Pero ¿por qué no podemos hablar entre nosotros? Hablar no es nada malo. ¿Por qué nos haces esto? Me dijo que porque éramos de la raza árabe. Le dije que era bereber pero a él le daba igual. A mí no me parece mal que me paren pero te paran sin ningún motivo, como si hubieses hecho algo malo, robar. Solamente paraban a los marroquís. (Joven marroquí 13)

Los motivos de los abusos policiales están relacionados con la impunidad que existe debido a la falta efectiva de derechos de los extranjeros no documentados. En un estudio realizado a finales de la década de los 90 en el barrio bilbaíno de San Francisco ya aparecía definida claramente esta problemática de abusos policiales sistemáticos, detenciones arbitrarias y malos tratos respecto a la población extranjera (Díaz y Fantova, 1998).

En las entrevistas también se percibe que la discriminación es mayor cuando el joven marroquí es más visible. Esto se produce por el efecto de los rasgos faciales, aunque también influye el número de menores que vayan en el grupo. Un grupo de jóvenes marroquíes será más fácilmente parado por la policía y tendrá más difícil la entrada a discotecas o bares.

Si vamos muchos, te puede parar la poli, te pueden cachear. (Joven marroquí 13)

Algunos son racistas y no nos dejan entrar... Depende del chaval. Si vas solo, entras. Si vas con 3 o 5, no. (Joven marroquí 3) 


\subsection{El estigma permanente, la frustración de sentirse diferente}

Además del racismo institucionalizado de los porteros de las discotecas o de los policías, las conductas racistas de la población autóctona hacia los jóvenes marroquíes se dan en muchos espacios públicos, en diferentes situaciones y por parte de personas con perfiles distintos, desde el tendero hasta la mujer que viaja en el transporte público.

Si entras al supermercado y tienes ganas de comprar, no de robar. Entran vigilantes y te vigilan. Si todos los días hacen lo mismo, algún día te vas a enfadar. Te vas a hablar con ellos. «Oye, que yo no voy a robar. Que he venido aquí a comprar»... En el metro también. Si tú lo ves que todo el mundo tiene miedo de ti, te enfadas, ¿no? Una vez discutí con una señora. Al final me pidió perdón. Yo entré en el metro, estoy así solo y de repente una persona mayor se ha levantado de su sitio y se fue a otro sitio. Luego, como tenía un bolsillo, abrió buscando para ver si estaban todas las cosas. Yo me fui a hablar con ella. «Oye, señora, por favor, ¿por qué has hecho eso?». (Joven marroquí 6)

El cierre de espacios sociales es una de las formas más agresivas de discriminación. Dificulta a los jóvenes relacionarse con la población autóctona, estar integrados con normalidad en la sociedad. Limita la posibilidad de «asimilación» y de aprendizaje de la cultura autóctona y obliga a los jóvenes que están integrados en cuadrillas autóctonas a apartarse de ellas:

Cuando iba con mis amigos vascos había discotecas que no me dejaban a mí y a ellos sí. En otras, cuando voy solo, no me dejaban y, cuando voy con chicos españoles, me dejaban. No sé si es porque tenía miedo de algo. Si vas con españoles es más fácil que te dejen entrar. En otras discotecas nunca te dejan entrar. En los bares donde no hay portero sí te dejan entrar. Los chavales vascos, uno estudiaba conmigo, sigue siendo mi amigo. Otro era amigo de mi amigo. Hace mucho tiempo que no he estado con ellos. Hablamos por el whatsapp. Como no me dejan, hace tiempo que no voy. Si vas de fiesta es para divertirte y si no te dejan entrar... por eso no quedamos con los amigos de aquí. Ahora no salgo mucho. En el tiempo libre voy a jugar al fútbol, a correr, a hacer cosas en casa. (Joven marroquí 13)

A continuación exponemos el testimonio de un joven que fue contratado como portero en un bar de copas de Barakaldo. Se aprecia en el testimonio cómo su trabajo le llevó a tener que enfrentarse con algunos compatriotas y apartarse de ellos. Se aprecia también la ambivalencia y el sentimiento de culpa del joven por tener que aplicar prácticas discriminatorias en contra de personas de su propio colectivo.

Mi trabajo de portero también me ha creado enemigos entre los marroquíes porque no les dejaba entrar. Pero yo es lo que buscaba. Porque me quería apartar de ellos. Me jode no dejarles. Estaban ahí en la esquina que no les dejan entrar como estaba yo. Cuando tienes una novia ella entra y tú no. Yo creo que por un pensamiento religioso está bien que no les dejen entrar. (Joven marroquí 5) 
La discriminación crea en los jóvenes marroquíes unos importantes problemas de identidad, especialmente en aquellos que tienen una mayor voluntad de asimilarse. El cierre de los espacios sociales, al poner de manifiesto el rechazo, enfrenta a los jóvenes marroquíes con su estigma de una manera violenta. Esto suele dar lugar a una conducta ambivalente que va desde el rechazo de la discriminación hasta su justificación, pasando por una negación de la misma. Es muy habitual que los jóvenes marroquíes reconozcan y sean conscientes de que existe una discriminación, pero que manifiesten no sufrirla personalmente. También suele aparecer el intento de justificar las conductas discriminatorias aludiendo a la conflictividad de algunos de los miembros del colectivo. El siguiente testimonio es un claro ejemplo de esa mezcla de frustración, negación, ambivalencia, impotencia y justificación del racismo del que se es objeto:

En una entrevista de trabajo, si no me cogen por ser marroquí, yo me voy. Yo muchas veces me echo. Yo no me puedo sentir inferior. Aunque me lo hagan yo paso de ello. Te intentan hacer daño pero se hacen daño a ellos mismos. Que no me dejen entrar a un local me pasó con 15 años; pero en Durango cuando la liaba. Si tú vas con gente de aquí, vas bien vestido, te dejan entrar. A mí como me pare alguien la tendrá, entonces para evitar eso no salgo. Yo intento escaparme. También lo entiendes porque yo he trabajo de eso. El que está es un "mandao». Cuando entran unos marroquíes a un bar, la gente sale. A mí nunca me han pedido el DNI. Porque éramos populares. Te dejaban entrar a todos los sitios. (Joven marroquí 5)

\subsection{Ocio segregado desde el sistema de intervención}

Desde los agentes educativos también se tiende, de alguna manera, a fomentar un ocio segregado. Es el caso del centro de Loiu que dispone de varios equipos deportivos propios, de fútbol y de atletismo. Estas experiencias se han presentado en los medios de comunicación como experiencias positivas de integración que contribuyen a que los menores extranjeros «laven» su imagen negativa. Refiriéndose al equipo de fútbol del centro Zabaloetxe un educador marroquí habla para El Correo:

Yo creo en el fútbol como vía de inserción social. Además de aprender valores, si practicas deporte, no fumas, no bebes, no te drogas. Cuando estoy con los chavales intento explicarles cómo funcionan las cosas aquí, cuáles son las reglas, cómo es la cultura. (El Correo 25-7-2011)

A pesar de que la participación en estos equipos deportivos "para marroquíes» tiene unos claros efectos positivos en los menores; podríamos decir también que, como contrapartida negativa, fomentan un ocio segregado que dificulta la integración normal de los menores impidiendo que se relacionen con jóvenes autóctonos en ambientes informales, que se empapen de la cultura autóctona, etc.

En el centro de Loiu también se formaron diferentes grupos de música tradicional marroquí que actuaban en fiestas fuera del pueblo. Estos grupos tienen una dimensión positiva 
porque contribuyen a que los menores conserven parte de su folclore y, además, lo exponen en actos públicos en la sociedad de acogida lo que es una contribución importante a la diversidad cultural y puede fomentar la tolerancia hacia lo diferente. Sin embargo, por otro lado, puede contribuir a fortalecer la diferencia. Además, el hecho de que estos grupos estén organizados desde el centro y, de esta manera, se le reste autonomía al menor para que organice su propio tiempo de ocio, también genera rechazo entre algunos chavales.

En Loiu estoy un año. Allí empezamos con el grupo de música. Al principio tocaba yo solo, me gustaba tocar la guitarra en Amorebieta y luego nos juntamos con los otros. (...) El centro nos propone formar el grupo pero somos nosotros el grupo. Al final no nos hacen caso. Es nuestra responsabilidad. Cobraban y no nos daban el dinero. (Joven marroquí 12)

En cualquier caso, la organización del tiempo de ocio en equipos deportivos «normalizados» puede contribuir a mejorar el capital social de los menores. Los equipos deportivos no segregados, por ejemplo, pueden llegar a ser un elemento importante de puesta en contacto de los jóvenes extranjeros con la población autóctona normalizada.

Desde el primer trabajo, conocí a un chico que es español y es buen chico y me ha llamado y me ha dicho que me juntara con ellos y siempre voy cuando hay partidos. A veces el domingo, a veces el sábado. Estamos en una liga. Todos son vascos. No quedo con ellos más que para jugar, solamente juego. Ellos suelen quedar, me invitan a la lonja pero no he querido ir. (Joven marroquí 1)

Allí [mezquita] no conozco gente, donde conozco mis amigos es en el fútbol. Son chavales vascos, salimos de fiesta o salimos a tomar algo. Seguimos jugando juntos. Con los que más quedo son con los del equipo. Jugamos un partido, lo terminamos y vamos de fiesta. Al resto de amigos vascos los he conocido porque son amigos de mis amigos. Es difícil que hagas amigos, por ejemplo, de fiesta. A mí nunca me han parado al entrar a las discotecas pero a mis amigos marroquís no les dejan. (Joven marroquí 2)

Antes jugaba al fútbol y ahora a taekwondo. Estoy en equipos. Nos enseñan mogollón los profesores. Empecé porque les dije a los educadores un día «me gusta apuntarme a un equipo de fútbol». Con los del equipo a veces quedamos con ellos. Tienen una lonja. Ahora llevo dos años sin jugar pero tengo relación con el entrenador, con todo. No he vuelto a jugar porque no tenía para pagar las tasas, de ciento y pico euros. En el taekwondo también conozco gente. Me apunté porque hablé con los educadores. Les dije «a mí me gusta esto». Fueron a hablar con el polideportivo. Me hicieron un hueco. Iba muy tímido, no conocía a nadie, apenas sabía castellano, fui encajando poco a poco. A veces voy a conocer más gente. (Joven marroquí 4)

La planificación del ocio desde las asociaciones es en ocasiones rechazada por algunos jóvenes que prefieren organizar su ocio de manera autónoma o que se sienten avergonzados de ese ocio planificado: 
Muchos no quieren ir a las actividades de ocio que organizamos desde la asociación. Por ejemplo, cuando vamos a la playa muchos nos dicen que no quieren ir porque, al ir un grupo grande de extranjeros con los educadores, la gente se les queda mirando. (Educadora de Mundutik Mundura)

Hay que reseñar, sin embargo, algunas prácticas en torno al ocio que han tenido un efecto positivo en la integración de los jóvenes inmigrantes. Es el caso del grupo de teatro «De Aquí y de Allá» de la asociación Goiztiri. Este grupo de teatro estaba compuesto por jóvenes autóctonos e inmigrantes y, a través de él, los jóvenes marroquíes establecieron contactos con lo que podríamos denominar población autóctona normalizada lo que contribuye positivamente a su integración.

Les conocimos en el grupo de teatro (a los jóvenes autóctonos). Ellos tocaron con nosotros... Ahora ensayamos juntos en el mismo local en el gaztetxe. Nosotros vamos a sus fiestas y ellos vienen a las nuestras. (Joven marroquí 18)

\section{LA MEZQUITA COMO UN LUGAR EXTRAÑO}

La totalidad de los jóvenes marroquíes entrevistados se considera musulmana. La variable religiosa va a ser un elemento importante tanto en su identidad como en las prácticas que van a llevar a cabo y las redes sociales en las que van a integrarse. A pesar de esa identidad musulmana común, veremos que ésta se concreta en prácticas muy heterogéneas y que existen diferencias importantes entre casos.

Es importante destacar el diferente papel que esa parte de la identidad tiene en la sociedad de origen y en la de acogida. El islam es una parte de la identidad que los menores traen consigo cuando llegan a Europa. Esta parte de la identidad estaba perfectamente integrada y cumplía una serie de funciones sociales centrales en el contexto y los campos sociales en los que los menores vivían en el país de origen; pero, al llegar a la Bizkaia e ingresar en el centro, la religión se convierte en una parte de la identidad que muestra un encaje difícil en la sociedad de acogida y, sobre todo, en el sistema de intervención con menores. La identidad musulmana es tratada en la sociedad de acogida como un problema, se pasa de una identidad omnipresente e incuestionable en el país de origen a una identidad que trata de ser eliminada del espacio público en el país de acogida.

Sin embargo, el menor marroquí todavía va a formar parte de un tejido social en el que la religión sigue siendo importante. La identidad religiosa se mantiene porque, a pesar de que la población autóctona la considera una identidad extraña, va a conservar una centralidad en las relaciones que mantienen los jóvenes marroquíes entre ellos, en las relaciones que mantienen con su familia a través del teléfono o internet, o en las relaciones con las diferentes mezquitas. 
Mis padres son musulmanes y me han enseñado que no bebo, que no como jamón ni nada. Yo respeto a mis padres. Yo he conocido desde el primer día la mezquita pero es diferente. No es como en Marruecos. En Marruecos oyes por el día (la llamada a la oración). Aquí todo va en silencio. (Joven marroquí 1)

Tenemos, por lo tanto, una situación en la que, a pesar de que el islam es una parte de la identidad de todos los menores marroquíes, esta parte de la identidad no va a tener un encaje natural en la sociedad de acogida, la práctica religiosa no es algo que viene dado, sino que el individuo tiene que hacer esfuerzos importantes para llevar a cabo alguna de ellas.

Esto va a provocar que exista una heterogeneidad importante entre los jóvenes marroquíes respecto a las prácticas religiosas. Existen jóvenes que llevan a cabo unas prácticas muy intensas que chocan con la forma de funcionar de la sociedad de acogida, y otros, por el contrario, practican su religión de una manera mucho más relajada, que incluso puede suponer el abandono de obligaciones como el rezo o prohibiciones como la ingesta de alcohol.

La religión es igual para todos. Pero algunos chavales cumplían con el rezo; otros, poco; otros nada...yo no rezo mucho, no como cerdo. Hay gente que reza a todas las horas y gente que no. Yo no rezo. El Ramadán sí que hago. A la mezquita, los viernes voy. (Joven marroquí 13)

Yo no suelo ir a la mezquita, no voy a rezar, somos musulmanes pero practicamos poco. Yo apenas practico. Mantengo lo de no comer cerdo. (Joven marroquí 4)

El control sobre otras prácticas religiosas se debilita de manera importante respecto a la situación en Marruecos, aunque no desaparece del todo y se va a ejercer a través de tres agentes. El primero es el propio grupo de menores en el que se da un control importante del cumplimiento de las obligaciones religiosas. El segundo va a ser la familia que, aunque en la distancia, sigue siendo una fuente importante de control de la identidad. El tercero va a existir especialmente en el caso de los jóvenes que acuden a las mezquitas y es la que podríamos denominar comunidad islámica en el país de acogida.

Especialmente en el caso de los centros que se encuentran apartados de los núcleos urbanos, el acudir a la mezquita supone para los menores un esfuerzo importante de desplazamiento e incluso económico e implica que, en muchos casos, se acuda a la mezquita solamente los fines de semana. El funcionamiento de los centros, la ubicación y los horarios hacen difícil, por lo tanto, que los menores puedan acudir a la mezquita entre semana.

Entre semana no hay tiempo. Hay viernes que no trabajamos y daban creditrans para bajar a la mezquita. Bajamos a la mezquita de Bilbao. (Joven marroquí 1)

Cuando estamos en Amorebieta (centro), sólo podemos ir el sábado. Si algunos tienen permiso, van a la mezquita, pero la mayoría se quedan allí. Ahora voy un día a la semana, el viernes. (Joven marroquí 3) 
Antes iba a la mezquita, ahora no. A Barakaldo, a la del Casco Viejo.... Con mis amigos de Loiu el sábado cuando salimos vamos a la mezquita lo primero a rezar, a llamar a la familia, damos una vuelta y luego a Loiu. Los fines de semana. (Joven marroquí 6)

El colectivo de jóvenes marroquíes es un colectivo que está, en gran medida, desconectado de la sociedad de acogida. A diferencia de otros colectivos inmigrantes, no migran a través de redes migratorias preexistentes que les permiten integrarse en una comunidad a su llegada al país de acogida; en este caso el factor que atrae la inmigración de menores es el propio sistema de acogida, por lo que estos menores no cuentan, en la mayoría de los casos, con referentes adultos que ya se encuentren incorporados con cierta estabilidad en la sociedad que les acoge. No tienen, en principio, contactos con la que podríamos denominar comunidad marroquí en Bizkaia. Tampoco con la comunidad musulmana. Los menores no pertenecen en principio a esta comunidad musulmana y el integrarse en la misma va a ser una labor que requiere, en muchos casos, un esfuerzo importante por parte de este colectivo.

El estigma de los menores marroquíes está también presente entre los miembros de la comunidad musulmana que, en ocasiones, culpan a los MENAs de deteriorar la imagen de los marroquíes o de los musulmanes.

Algunos (de los adultos que asisten a la mezquita) mantienen la distancia. Conocen a la gente del centro y en la gente del centro hay ladrones. (Joven marroquí 1)

Al fin y al cabo esos jóvenes, si actúan mal, se perjudican a sí mismo y dan mala imagen de los musulmanes que no es la más adecuada. Apoyan lo que sale en los medios de comunicación aparte de que nos definen como terroristas, como integristas y como todo los «istas». Aparte unos chavales que luego a la primera le dicen: no, no, yo no como cerdo porque soy musulmán. Reclaman que no comen cerdo porque «soy musulmán». Pero no reclaman que tampoco pueden beber alcohol, tampoco pueden hablar mal a los mayores, tampoco pueden perder su tiempo, tampoco tienen que desaprovechar los medios que les están facilitando, tampoco tienen que dejar de servir a la sociedad. (Representante mezquita)

Vemos, por lo tanto, que el colectivo de menores marroquíes no está naturalmente integrado en la comunidad musulmana y que, además, el estigma que sufren está presente también en dicha comunidad. Para establecer relaciones con esta comunidad el menor debe acudir a la mezquita e, incluso, colaborar en las actividades que en la misma se desarrollan, lo que requiere una actitud activa y un esfuerzo importante. 


\section{CONCLUSIONES}

Podemos decir que la mayoría de las dinámicas sociales en las que se ven implicados los menores marroquíes en Bizkaia conducen a un aislamiento social significativo respecto a la población autóctona, incluso, a un aislamiento relativo respecto a la propia población inmigrante marroquí. Denominaremos a esta situación cuarentena social. El Estado tiene un papel fundamental en este proceso, definiendo las condiciones de inserción de los menores en el sistema residencial y en el sistema educativo, y restringiendo mediante la acción policial el uso del espacio público. La cuarentena es definida también en base a otras dinámicas sociales más informales como la discriminación en el acceso a determinados espacios de socialización como los bares y discotecas.

El aislamiento de los menores marroquíes se da también respecto a la «comunidad» musulmana establecida en Bizkaia. Aunque algunos menores acuden a la mezquita y establecen relaciones con otros musulmanes, el funcionamiento del sistema de protección dificulta que esto pueda producirse. Además, el estigma de conflictividad asociado a las dinámicas de los centros de menores está presente también en la comunidad musulmana.

A pesar de que la mayor parte de las dinámicas sociales dan lugar al aislamiento del grupo, se han identificado ciertas vías a través de las cuales existe contacto con población autóctona. Así, el acceso a centros educativos orientados al fracaso escolar, a equipos deportivos y las relaciones con las chicas son tres vías a través de las cuales los menores marroquíes establecen relaciones igualitarias con la población autóctona y podrían dar acceso a estrategias de capital social y a la adquisición de repertorios culturales autóctonos.

Aunque no se ha desarrollado en este artículo, y como contrapartida positiva, conviene apuntar que la cuarentena social tiene también como consecuencia el fortalecimiento de los lazos entre los propios jóvenes marroquíes. Aunque en un primer momento este grupo es poco coherente debido a los orígenes diversos de los menores extranjeros y a las diferencias culturales existentes entre los mismos, la acción de las administraciones a través del internamiento crea un grupo social con unas características y unas trayectorias vitales que le proporcionan una cohesión importante. Como apuntaba Barth (1976) son las fronteras y no el contenido cultural las que definen los grupos étnicos. Un grupo aislado con unas fronteras tan fuertemente definidas termina por presentar una cohesión creciente. En este sentido, como ha apuntado un estudio realizado para el caso de la CAV, existen fuertes redes de solidaridad entre los jóvenes inmigrantes en Bizkaia (Fundación EDE 2011), unas redes que les permiten adaptarse a un entorno hostil y sobreponerse al aislamiento que la sociedad de acogida les impone. 


\section{BIBLIOGRAFÍA}

Ararteko. (2005). Situación de los Menores Extranjeros No Acompañados en la CAPV. Informe Extraordinario del Ararteko al Gobierno Vasco. http://www.ararteko.net/ RecursosWeb/DOCUMENTOS/1/1_10_3.pdf

Ararteko. (2011). Infancias vulnerables. Informe Extraordinario del Ararteko al Gobierno Vasco. http://www.ararteko.net/RecursosWeb/DOCUMENTOS/1/1_2354_3.pdf

Barth, F. (1976). Los grupos étnicos y sus fronteras: la organización social de las diferencias culturales. México: Fondo de cultura económica.

Borocz, J. y Portes, A. (1989). Contemporary immigration: theoretical perspectives on its determinants and modes of incorporation. The International migration review, 23(3), 606-630.

Bourdieu, P. (1986). «The forms of capital». In Richardson, J. Handbook of Theory and Research for the Sociology of Education. New York: Greenwood Press

Bravo, A., y Santos-González, I. (2017). Menores extranjeros no acompañados en España: Necesidades y modelos de intervención. Psychosocial Intervention, 26(1), 55-62. https://doi.org/10.1016/j.psi.2015.12.001

Burt, R. S. (2001). Strucural Holes versus Network Closute as Social Capital. En Lin, Nan; Cook, Karen S. y Burt, Ronald S. Social capital: theory and research (pp. 31-56). Transaction Publishers.

Cónsola Párraga, M. (2016). «La atención socioeducativa de los menores extranjeros no acompañados. Una mirada hacia las expectativas y las necesidades». Educació Social. Revista d’Intervenció Socioeducativa, 64, p. 44-60.

Díaz, B. y Fantova, J. (1998). El color de la sospecha. El maltrato policial a personas inmigrantes en el barrio de San Francisco (Bilbao). Bilbao: Likiniano Elkartea. http:// centroderecursos.alboan.org/es/registros/1372-el-color-de-la

Fernández, B. y Barba, M. (2014). Los jóvenes inmigrantes marroquíes en el sistema educativo de Bizkaia: diferentes inserciones y sus efectos en términos de capital social. Inguruak. Revista vasca de sociología y ciencia política, (57), 2595-2606.

Fernández, M., Valbuena, C. y Caro, R. (2017). Evolución del racismo, la xenofobia y otras formas de intolerancia en España. Informe- encuesta 2017. Observatorio Español del Racismo y la Xenofobia. http://www.mitramiss.gob.es/oberaxe/ficheros/documentos/ Informe-Racismo-2017.pdf 
Fundación EDE. (2011). Relaciones de solidaridad entre inmigrantes: acercamiento a las redes informales de apoyo de menores y jóvenes no acompañados en la CAPV. Publicación de la Fundación EDE. (http://www.fundacionede.org/ca/archivos/ investigacionsocial/22-Relaciones-solidaridad-entre-inmigrantes-menores-jovenesno-acompanados.pdf)

Gozalo, A.; Jiménez, E. y Vozmediano, L. (2010). ¿Menores o extranjeros? Análisis de las políticas de intervención sobre menores extranjeros no acompañados. Publicación del Ararteko. http://www.ararteko.net/RecursosWeb/DOCUMENTOS/1/1_2226_3.pdf

Granovetter, M. S. (1973). The Strength of Weak Ties. The American Journal of Sociology, 78(6), 1360-1380.

Ikuspegi. (2018). Barómetro 2018. Percepciones y actitudes hacia la inmigración extranjera. Ikuspegiak. Observatorio Vasco de la Inmigración. http://www.ikuspegi.eus/ documentos/barometros/2018/bar_CAE_2018_CAS_web.pdf

Light, I. (1984). Immigrant and Ethnic Enterprise in North America. Ethnic and Racial Studies, Vol. 7, Issue 2, 195-216.

Mendoza, K. y Belarra, I. (2015). Menores Migrantes en Bizkaia: Entre la protección y el control. Revista Internacional de Estudios Migratorios (RIEM), 5(2), 227-259.

Portes, A. (1998). Social Capital: Its Origins and Applications in Modern Sociology. Annual Review of Sociology, 24(1), 1-24.

Putnam, R.D. (2007). «E Pluribus Unum: Diversity and Community in the Twenty-first Century». Scandinavian Political Studies, 30(2), 137-174.

Quiroga, V.; Alonso, A. y Soria, M. (2009). Sueños de bolsillo. Menores Migrantes No Acompañados en el País Vasco. Servicio Central de Publicaciones del Gobierno Vasco. http://www.surgam.org/articulos/510/Suenyos\%20de\%20bolsillo\%20Castellano.pdf

Setién, M. L. y Barcelo, F. (2007). La atención a los MENAs en el País Vasco. Modelos de intervención y luces y sombras en el sistema de acogida. Actas del Coloqui Internacional: La migración de Menores extranjeros no Acompañados en Europa. Poitiers 11-12 octubre 2007.

Swilder, A. (1986). Culture in Action: Symbols and Strategies. American Sociological Review, 51(2), 273-286. 
Los menores marroquíes en Bizkaia, un colectivo en cuarentena social | Mikel Barba del Horno

Waldinger, R. D. (1997). Social Capital or Social Closure? Immigrant Networks in the Labor Market. UC Los Angeles: The Ralph and Goldy Lewis Center for Regional Policy Studies.

Yin, R. K. (2003). Applications of case study research. SAGE. 